\title{
SECULAR AND LONG-TERM VARIATIONS \\ OF THE POLAR MOTION
}

\author{
E. PROVERBIO \\ International Astronomical Station, Carloforte-Cagliari, Italy \\ and \\ F. CARTA and F. MAZZOLENI \\ Astronomical Observatory, Brera-Milano, Italy
}

\begin{abstract}
An analysis on the secular motion of the pole has been carried out utilising the latitude observations of the ILS stations reduced to the $\emptyset_{\mathrm{II}}{ }^{(\mathrm{i})}$ system (Proverbio et al., 1969).

The existence of long periodic terms in the polar motion as found out by Markowitz (1960) was confirmed.

The secular displacement of the polar motion calculated abstracting from long period terms results 0 "00294 for year along the meridian $65^{\circ} .6 \mathrm{~W}$.

A probable drift of continental blocks with average Northward rate of 1-2 cm/year for Eurasia and $1 \mathrm{~cm} /$ year for North America has been suggested. The possible drift emphasized for Japan is on the contrary of $1 \mathrm{~cm} /$ year southwards.
\end{abstract}

\section{Reference System}

The existence of a secular motion of the pole is confirmed by the analyses of the latitudes of the ILS stations carried out in the last few decades. Yet this phenomenon presents some disturbances that have been differently interpreted by various authors (Markowitz, 1960, 1968; Yumi and Wako, 1969).

\section{Mean Latitude and Annual Variations}

The latitudes of the five ILS station of 1900.0-1961.9 in the $\varnothing_{\text {II }}$ system (Proverbio et al., 1969) have been filtered using OR2 $=Y_{1 / 2} Y_{3} s_{9 / 2} / 40$ and the $\mathrm{F} 60=s_{59 / 2} / 60$ filter in the Labrouste notation.

The mean latitude and variations for the five ILS stations are calculated by the method of least squares using equations of the form:

$$
\begin{aligned}
& \emptyset_{\mathrm{II}}^{\mathrm{F} 60}=a_{0}+a_{1}(t-1903.0), \\
& \emptyset_{\mathrm{II}}^{\mathrm{OR} 2}=a_{0}^{\prime}+a^{\prime}(t-1903.0) .
\end{aligned}
$$

In Table I the conventional mean latitudes of the five ILS stations in the new CIO system are given (less the $39^{\circ} 8^{\prime}$ constant), together with the values of the $a_{0}$ and $a_{0}^{\prime}$, quantities.

In the same table are also given the values obtained applying the six-year filter (F60) and the Orlov filter to the latitudes of the period 1900.0-1906.0, that is for the mean epoch 1903.0 .

The values of the yearly variations of the latitudes $a_{1}$ and $a_{1}^{\prime}$ deduced by means of (1) are instead collected in Table II.

Supposing a uniform straight motion $u$ of the pole along the meridian $v$, by means 
TABLE I

\begin{tabular}{|c|c|c|c|c|c|}
\hline & MIZ & KIT & CAR & GAI & UKI \\
\hline F60 & 3".589 & - & $8 " 948$ & 13".195 & $12 " 086$ \\
\hline OR2 & 3 ".575 & - & $8 " 925$ & $13 " .230$ & $12 " .082$ \\
\hline$a_{0}$ & $3 " 565$ & 1".787 & $8: 926$ & $13 " 218$ & 12 ".091 \\
\hline & $\pm 0^{\prime \prime} \cdot 001$ & $\pm 0 ! 004$ & \pm 0.002 & \pm 0.002 & \pm 0 \\
\hline$a_{0}^{\prime}$ & $3 " 569$ & 1".776 & $8 " 927$ & 13 ".216 & $12 " 087$ \\
\hline & $\pm 0^{\prime \prime} 001$ & \pm 0.003 & $\pm 0 ! 002$ & $\pm 0^{\prime \prime} .002$ & $\pm 0,002$ \\
\hline ILS & 3"602 & 1 1"850 & 8".941 & 13"202 & $12 " 096$ \\
\hline
\end{tabular}

TABLE II

\begin{tabular}{|c|c|c|c|c|c|}
\hline & $\begin{array}{l}\text { MIZ } \\
(0 ! 001)\end{array}$ & $\begin{array}{l}\text { KIT } \\
\left(0^{\prime \prime} 001\right)\end{array}$ & $\begin{array}{l}\text { CAR } \\
\left(0^{\prime \prime} 001\right)\end{array}$ & $\begin{array}{l}\text { GAI } \\
\left(0^{\prime \prime} 001\right)\end{array}$ & $\begin{array}{l}\text { UKI } \\
(0 ! 001)\end{array}$ \\
\hline$a_{1}$ & $-2 ! .597$ & $-0 ! 826$ & $+1 " 288$ & $+2 " 1718$ & $+2 " 263$ \\
\hline & $+0 ! 001$ & $\pm 0 ! 017$ & $\pm 0 ! 002$ & $\pm 0 ! 002$ & \pm 0.001 \\
\hline$a_{1}^{\prime}$ & -2 ".701 & $-0^{\prime} 687$ & +11295 & $+2 ! 805$ & $+2 \prime 438$ \\
\hline & $\pm 0 ! 001$ & \pm 0.014 & \pm 0.002 & $\pm 0^{\prime} \cdot 001$ & $\pm 0^{\prime \prime} 001$ \\
\hline $\bar{a}_{1}$ & $-2 " 64$ & $-1^{\prime \prime} .69$ & $+1 " 06$ & $+2 ! \cdot 70$ & $+1 " .27$ \\
\hline $\bar{a}_{1}^{\prime}$ & $-2 ! .74$ & $-1 " .71$ & $+1 " 14$ & $+2 " .78$ & $+1 " .27$ \\
\hline $\bar{a}$ & $-2 " .29$ & $-1^{\prime \prime 2} 25$ & $+1 " .50$ & $+3 " .05$ & $+1 " 64$ \\
\hline
\end{tabular}

of equations of the type

$$
a_{1}^{(i)}=u_{1} \cos \left(\lambda^{(i)}-v_{1}\right),
$$

can be obtained the following most probable values of the parameters: $u_{1}=0$ " $00283 / \mathrm{yr}$ and $v_{1}=59.8 \mathrm{~W}$ with the data from $\mathrm{F} 60$, and $u_{1}^{\prime}=0.00293 / \mathrm{yr}$ and $v_{1}=58.9 \mathrm{~W}$ with the data from OR2. From these were obtained the values calculated from the yearly latitude variations $\tilde{a}_{1}$ and $\tilde{a}_{1}^{\prime}$ given in Table II.

The further introduction of a constant term $w$ common to all stations in (2) leads to the following results for the latitudes drawn from F60: $u_{1}=0.00277 / \mathrm{yr}, \quad v_{1}=60.7 \mathrm{~W}, \quad w=0.00043+0.00019 / \mathrm{yr}$.

The corresponding annual variations $\bar{a}$ of the latitudes with these values are reported in Table II.

\section{Coordinates and Variations of the Mean Pole}

The study of the long-term variations of the polar motions has been carried out by analysing the coordinates $x$ and $y$ by means of relations of the type:

$$
\begin{aligned}
& (x, y)=a+b t+c_{1} \sin 2 \pi(t / T)+c_{2} \cos 2 \pi(t / T), \\
& (x, y)=a^{\prime}+b^{\prime} t+d^{\prime} t^{2}+c_{1}^{\prime} \sin 2 \pi(t / T)+c_{2}^{\prime} \cos 2 \pi(t / T)
\end{aligned}
$$

calculating the parameters $a, b, c_{1}, c_{2}$, and $a^{\prime}, b^{\prime}, d^{\prime}, c_{1}^{\prime}$ and $c_{2}^{\prime}$ as a function of the $T$ period, variable from 20 to $40 \mathrm{yr}$ with two-year steps.

In Figures 1 and 2 are given the diagrams of the amplitudes $A_{x}$ and $A_{y}$ of the com- 


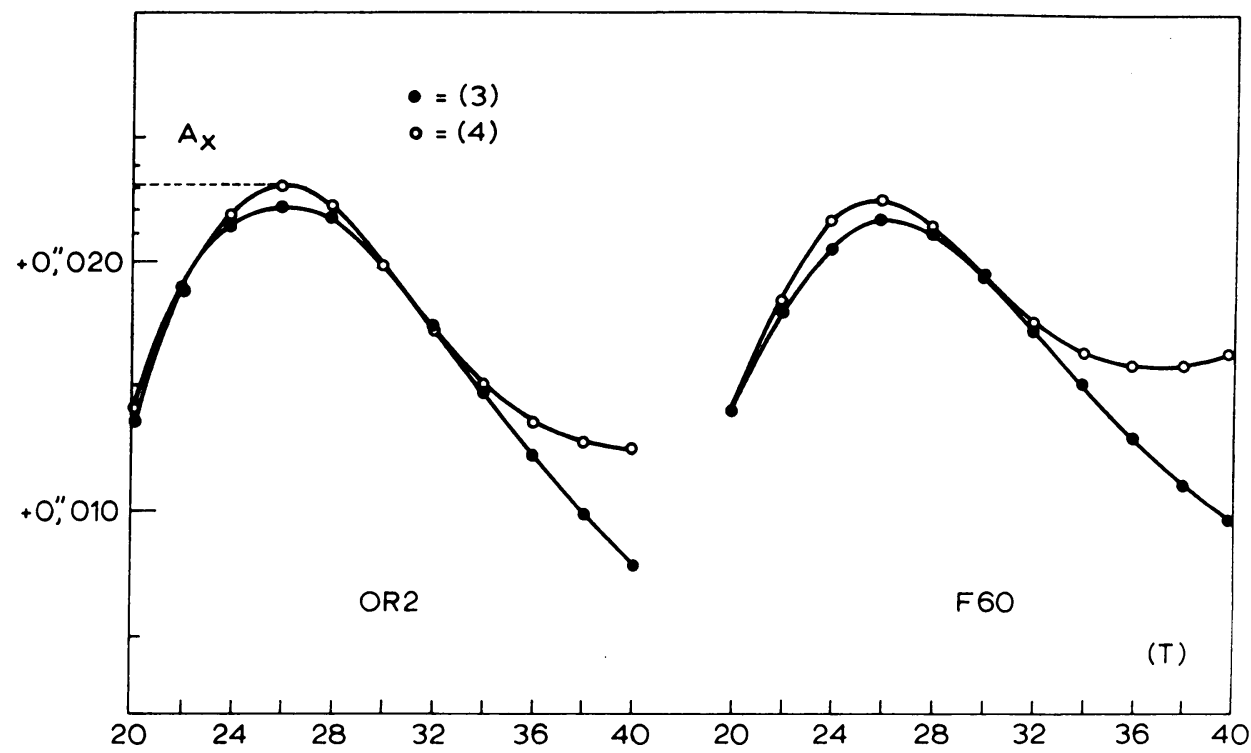

Fig. 1.

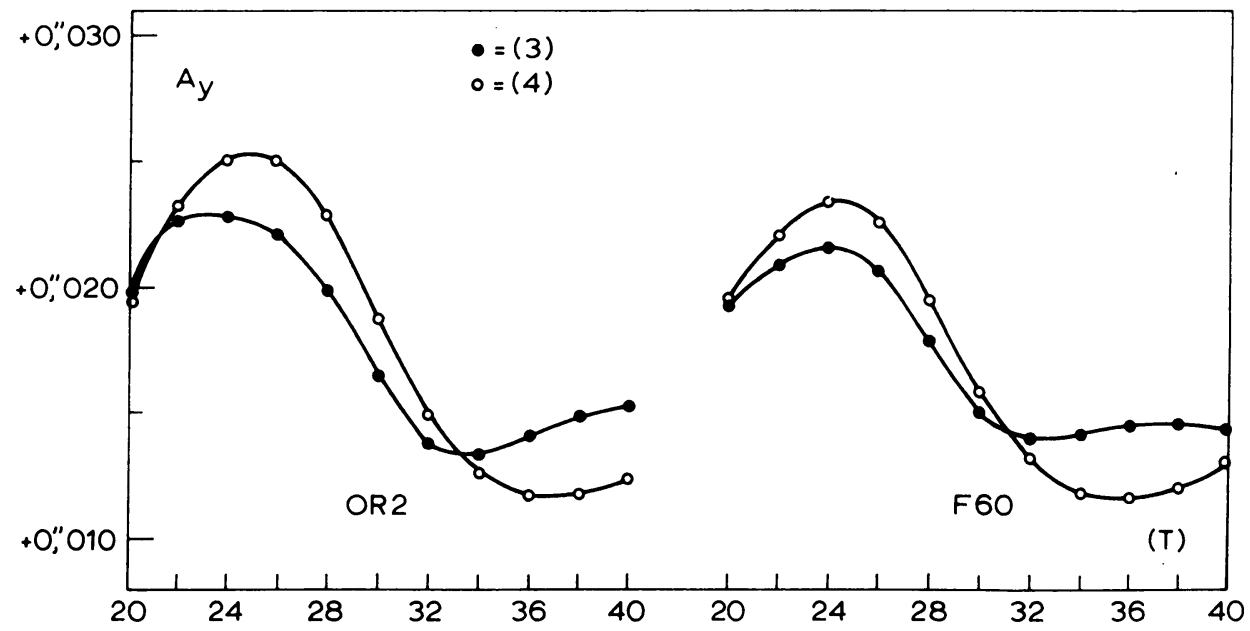

Fig. 2.

ponents of the period (variable from 20 to $40 \mathrm{yr}$ ) calculated with the coefficients $c_{1}$, $c_{2}, c_{1}^{\prime}$ and $c_{2}^{\prime}$ which characterize the trend of the $x$ and $y$ polar coordinates. A long-term component can be singled out in the polar motion, represented by the equations

$$
\begin{aligned}
& x=0.023 \sin \left(\begin{array}{l}
2 \pi t \\
26
\end{array}+170^{\circ}\right), \\
& y=0.024 \sin \left(\frac{2 \pi t}{24}+120^{\circ}\right),
\end{aligned}
$$


in which, the initial epoch $t_{0}=0$ can be made to coincide to a first approximation with the epoch 1902.0 .

Taking into account both the constant quantities and the long-term periods the latitude variations and the corresponding yearly variations of the $(\mathrm{O}-\mathrm{C})$ values reported in Table III have been calculated.

The values given in Table III seem to confirm the hypothesis of a secular shifting of the Euro-Asiatic bloc of about $1-2 \mathrm{~cm} /$ per year towards $\mathrm{N}$ (the heavy shifting of KIT is almost certainly due to the short interval of observation of this station and to the extrapolation errors) and of a shifting in the same direction of North America of the order of $1 \mathrm{~cm} /$ per yr, while the Japan area seems to be moving by about the same amount towards the equator.

TABLE III

$\begin{array}{lll} & (\mathrm{O}-\mathrm{C})^{*}{ }_{\mathrm{F} 60} & (\mathrm{O}-\mathrm{C})^{*}{ }_{\mathrm{OR} 2} \\ & & \\ & \left(0^{\prime \prime} 001\right) & \left(0^{\prime} .001\right) \\ \text { MIZ } & -0.20 & -0.27 \\ \text { KIT } & +0.89 & +1.06 \\ \text { CAR } & +0.48 & +0.45 \\ \text { GAI } & +0.19 & +0.15 \\ \text { UKI } & +0.28 & +0.39\end{array}$

Details are described in Proverbio et al. (1970).

\section{References}

Hattori, T.: 1959, ILOM 3, 1.

Markowitz, W.: 1960, Method and Techniques in Geophysics, Interscience Publ. Ltd., p. 235.

Markowitz, W.: 1963, in W. Markowitz and B. Guinot (eds.), 'Continental Drift, Secular Motion of the Pole, and Rotation of the Earth', IAU Symp. 32, 25.

Proverbio, E., Carta, F., and Mazzoleni, F.: 1969, Contr. Obs. Astron. Milano, No. 319.

Proverbio, E., Carta, F., and Mazzoleni, F.: 1970, Compt. Rend. Sem. Fac. Sci. Univ. Cagliari, XLI, Yumi, S. and Wako, Y.: 1970, in Mansinha et al. (eds.), Earthquake Displacement Fields and the Rotation of the Earth, D. Reidel Publ. Co., Dordrecht-Holland, p. 82. 